\title{
Assessment of necessity of neuronavigation in localization of clavarial extra-axial lesions in the setting of limited resources.
}

Hussein Soffar

Cairo University Kasr Alainy Faculty of Medicine

Mohamed F. Alsawy ( $\sim$ mohamed.elsawy@kasralainy.edu.eg )

Cairo University Kasr Alainy Faculty of Medicine https://orcid.org/0000-0002-1481-2494

\section{Research}

Keywords: Claverial, Extra-axial, Meningioma, Neuronavigation, Streotaxy

Posted Date: January 11th, 2021

DOI: https://doi.org/10.21203/rs.3.rs-58119/v2

License: (c) (i) This work is licensed under a Creative Commons Attribution 4.0 International License.

Read Full License

Version of Record: A version of this preprint was published at Chinese Neurosurgical Journal on August 2nd, 2021. See the published version at https://doi.org/10.1186/s41016-021-00253-1. 


\section{Abstract}

BACKGROUND: Neuronavigation is a very beneficial tool in modern neurosurgical

practice. However, the neuronavigation is not available in most of the hospitals in our country raising the question about its importance in localizing the clavarial extra-axial lesions and to what extent it is safe to operate without it.

METHODS: We studied twenty patients with clavarial extra-axial lesions who underwent surgical interventions. All lesions were preoperatively located with both neuronavigation and the usual linear measurements. Both methods were compared regarding the time consumed to localize the tumor and the accuracy of each method to anticipate the actual center of the tumor.

RESULTS: The mean error of distance between the planned center of the tumor and the actual was $6.50 \pm 1.762 \mathrm{~mm}$ in conventional method, whereas the error was $3.85 \pm 1.309 \mathrm{~mm}$ in IGS method. Much more time was consumed during the Neuronavigation method including booting,

registration, positioning. A statistically significant difference was found between the mean time passed in the conventional method and IGS method $(2.05 \pm 0.826,24.90 \pm 1.334$, respectively), P-value $<0.001$.

CONCLUSION: in the setting of limited resources, the linear measurement localization method seems to have an accepted accuracy in localization of clavarial extra-axial lesions and it saves more time than neuronavigation method.

\section{Background}

Neuronavigation is a very beneficial tool in modern neurosurgical practice. Sometimes it is nearly impossible to start an operation without its availability especially in small and deep lesions such as glioma and brain metastasis[1].

On the other hand, the necessity of neuronavigation usage is questionable especially in the convexity lesions like meningiomas[2]. Given into consideration the price of the machine and the accompanying sophisticated radiological studies, the enthusiasm becomes weaker to have such a technology as a prerequisite to perform a meningioma resection. Unfortunately, the image guided surgery (IGS) is not available in most hospitals in our country raising the question about its importance in localizing the clavarial extra-axial lesions mainly meningiomas and to what extent it is safe to operate without it.

\section{Methods}

We prospectively studied twenty patients with calvarial convexity meningiomas who would have surgical interventions. The patients were operated upon in the authors' institute in the period between July 2018 to February 2019. 
Data collection: preoperative evaluation of all patients was done by history taking, neurological and radiological assessment. We excluded the recurrent cases from our study. All the patients had a preoperative CT (Computed Tomography) scan protocol which is compatible with the IGS system. CT scans were performed using a multi-slice CT scanner (Siemens ${ }^{\circledR}$ Somatom Emotion, Erlangen, Germany). MRI (Magnetic Resonance Imaging) study for the brain was done for all the patients before and after administration of IV contrast was done and MRV (Magnetic Resonance Imaging) was done in some cases. MRI was performed using 1.5 Tesla MRI-System (Achieva ${ }^{\circledR}$, Philips Healthcare, Best, Netherlands). All lesions were preoperatively located with both neuronavigation and linear measurement methods. The intraoperative image guidance was done via (StealthStation $₫$ S7 $₫$ System, Medtronic,Inc, Louisville, CO, USA ), whereas the usual linear measurements were based on craniometric points.

Assessment: Both methods were compared regarding the time consumed to localize the tumor and the accuracy of each method to anticipate the actual center of the tumor. Accuracy of the localization was checked after full exposure of the tumor and applying intraoperative measurements comparing both methods. The calculated time started immediately after the finishing of anesthetic procedures till planning of an appropriate skin flab was finished. Data was analyzed using Paired Sample T-test via the Statistical Package of Social Science (SPSS) advanced statistics version 25 (IBM Inc ${ }^{\circledR}$, Chicago, IL, US).

\section{Results}

This study included 20 patients with calvarial extra axial lesions. The mean age at the time of surgery for the studied group was 50.6 years ranging from 20 to 70 years. There was a female predominance. There were 14 females $(70 \%)$ and 6 males $(30 \%)$ which provide a female/male ratio of $(2.33 / 1)$. The lesion was left sided in 11 cases (55\%) and right sided in 7 cases (35\%) and midline in 2 cases (10\%). The duration of the presenting symptoms ranged from 2 week to 3.5 years with a mean of 8 months. Headache was the most common feature occurring in $75 \%$. Seizures were the main complaint in $20 \%$ of cases. Weakness and numbness occurred in $10 \%$ of cases and two patients $(10 \%)$ presented with an altered level of consciousness (Table 1). All the patients had total tumor excision and the pathology was Meningioma in all cases.

A statistically significant difference was found between the mean time passed in the conventional method and IGS method $(2.05 \pm 0.826,24.90 \pm 1.334$, respectively), P-value $<0.001$. Also, a statistically significant difference was found between conventional method and brain lab one in the prediction of the center of the tumor. The mean error of distance between the planned center of the tumor and the actual was $6.50 \pm 1.762 \mathrm{~mm}$ in conventional method, whereas the error was $3.85 \pm 1.309 \mathrm{~mm}$ in IGS method with P-value $<0.001$ (Table 2).

\section{Table 1}




\begin{tabular}{|c|c|c|c|c|c|}
\hline Patient no & Age & Sex & Presentation & Tumor site & Symptoms duration \\
\hline 1 & 44 & $\mathrm{~F}$ & Headache & Left & 14 months \\
\hline 2 & 56 & M & Disturbed conscious level & Right & 2 weeks \\
\hline 3 & 52 & $\mathrm{~F}$ & Headache & Left & 9 months \\
\hline 4 & 61 & $\mathrm{~F}$ & Disturbed conscious level & Left & 2 weeks \\
\hline 5 & 56 & M & Headache & Left & 6 months \\
\hline 6 & 20 & $\mathrm{~F}$ & Headache \& Seizures & Right & 3 months \\
\hline 7 & 48 & $\mathrm{~F}$ & Headache & Midline & 24 months \\
\hline 8 & 47 & $\mathrm{~F}$ & Seizures & Right & 2 months \\
\hline 9 & 42 & M & Seizures & Left & 5 months \\
\hline 10 & 39 & $\mathrm{~F}$ & Headache & Right & 7 months \\
\hline 11 & 65 & $\mathrm{~F}$ & Headache & Right & 12 months \\
\hline 12 & 62 & $M$ & Headache & Left & 10 months \\
\hline 13 & 41 & $\mathrm{~F}$ & Headache & Left & 7 months \\
\hline 14 & 53 & $\mathrm{~F}$ & Headache & Right & 2 months \\
\hline 15 & 70 & M & Headache \& Weakness & Left & 2 months \\
\hline 16 & 60 & $\mathrm{~F}$ & Headache & Midline & 42 months \\
\hline 17 & 57 & $\mathrm{~F}$ & Headache & Left & 5 months \\
\hline 18 & 66 & $\mathrm{~F}$ & Headache & Left & 11 months \\
\hline 19 & 37 & M & Headache \& Weakness & Left & One month \\
\hline 20 & 36 & $\mathrm{~F}$ & Seizures & Right & 3 months \\
\hline
\end{tabular}

Demographics of the patients included in the study with the presenting symptoms and their duration and the site of the lesions.

Table 2 


\begin{tabular}{|c|c|c|c|c|c|}
\hline & & $\begin{array}{l}\text { Time of } \\
\text { conventional } \\
\text { (min) }\end{array}$ & $\begin{array}{l}\text { Time of brain } \\
\text { lab (min) }\end{array}$ & $\begin{array}{l}\text { Error in } \\
\text { conventional } \\
(\mathrm{mm})\end{array}$ & $\begin{array}{l}\text { Error in brain } \\
\text { lab }(\mathrm{mm})\end{array}$ \\
\hline \multicolumn{2}{|l|}{ Mean } & 2.05 & 24.90 & 6.50 & 3.85 \\
\hline \multicolumn{2}{|l|}{ Median } & 2.00 & 25.00 & 6.50 & 4.00 \\
\hline \multicolumn{2}{|c|}{ Std. Deviation } & .826 & 1.334 & 1.762 & 1.309 \\
\hline \multicolumn{2}{|l|}{ Minimum } & 1 & 23 & 4 & 2 \\
\hline \multicolumn{2}{|l|}{ Maximum } & 3 & 27 & 9 & 6 \\
\hline \multirow[t]{3}{*}{ Percentiles } & 25 & 1.00 & 24.00 & 5.00 & 3.00 \\
\hline & 75 & 3.00 & 26.00 & 8.00 & 5.00 \\
\hline & $\begin{array}{l}\mathrm{P} \\
\text { value }\end{array}$ & $<0.001$ & & $<0.001$ & \\
\hline
\end{tabular}

Descriptive analysis of the data of the 20 patients regarding accuracy and time consumed in both methods of tumor localization.

\section{Discussion}

No one can deny the importance of neuronavigation facilities which became a cornerstone in most of the neurosurgical theaters worldwide. In the late eighties of the last century, there was a revolutionary appearance of spatial neuroimaging together with pointing instruments that provided three dimensional data, which in turn led to the development of "frameless stereotaxy" concept which consequently yielded the expression of "Navigation systems" after improvement of guidance and orientation abilities [3].

Multiple modalities of navigation systems then appeared with increasing efficiency to the extent that they helped the neurosurgeons to plan different procedures interactively, making the approaches less invasive and more accurate especially for subcortical lesions[4-6]. but on the other hand those facilities failed to achieve so much popularity among the society of neurosurgery regarding routine craniotomies.[1]

In most cases of clavarial meningiomas and other extra-axial lesions, the neurosurgeon may not be compelled to use neuronavigation since most of the lesions are easily accessible immediately after craniotomy [2]. The only concern that might be worrying in those cases is the size of craniotomy. A suitable size in many opinions is to be slightly larger than the tumor size, giving the surgeons the space needed for dissection of the tumor away from neurovascular structures, on the other hand a small flab makes the surgery more difficult and more risky, also an extremely larger flab carries the risk of more blood loss and unnecessary exposure of normal neural structures [7]. 
Despite the expenses of installment of intra-operative navigation system, Paleologos et al found that cumulative cost for the overall hospital stay is cheaper when the clavarial meningiomas were operated with IGS. They took in consideration a lot of factors including the extra radiological work up that is needed for the navigation guidance and still it was cheaper, they attributed the decreased cost to less ICU (Intensive Care Unit) stay and less postoperative complications in the meningioma patients operated by navigation[2]. But even with this assumption, many tertiary care hospitals in our country lack navigation devices in their operation rooms (OR) due to budgetary difficulties that render purchasing of both hardware and software of the navigation systems primarily, which in turn reduce the dependence on these technologies among the neurosurgeons. Consequently, the neurosurgeons throughout our country, reserve the navigation assistance to operate upon deep and small lesions in more equipped yet few centers. So, we conducted this study to check if it is safe to operate upon clavarial meningiomas without navigation. Although we found a statistical significance between the conventional and IGS methods in anticipating the tumor center, yet we believe that the conventional method is of accepted accuracy and the error difference for each case is trivial as long as the conventional method was carried out by a senior and well trained neurosurgeon. Sun et al also concluded that surgical planning for parasagittal meningiomas removal can be conducted safely using the craniometric points[8].

Of course the presence of navigation within OR settings is reassuring to the neurosurgeon, one can feel more confident while operating, knowing that there is an available tool that can help in accurate planning of the surgery with good anticipation for any nearby vascular structures[9][10], yet the neurosurgeons in the developing countries can bear with more worrying feelings for the sake of curing patients from this benign tumors in the limited resources setting whenever it is safe to operate.

On the contrary, the linear method has a relative advantage over IGS in reducing the overall anesthesia time. We found a statistically significant difference in planning time between both methods, the IGS requires several steps to be functioning probably, whereas the linear method requires much simpler steps in localization with accepted accuracy counting on the experience of the surgical team to translate the radiological studies and to match the tumor location to the patients' cranium based on the anatomical landmarks. This reduction in anesthesia time could help in decreasing the rate of extracranial complications such as venous thromboembolic episodes [11,12], postoperative pneumonia[13] and Urinary tract infections[14].

\section{Conclusion}

In the setting of limited resources, the intra-operative linear measurement localization of convexity meningiomas and other extra axial lesions seems to be safe and have an accepted accuracy especially 
when conveyed by an experienced neurosurgeon. Moreover, it saves more time than the neuronavigation method decreasing the incidence of extracranial complications of prolonged anesthesia.

\section{Abbreviations}

CT: Computed Tomography; ICU: Intensive Care Unit; IGS: Image Guided Surgery; MRI: Magnetic Resonance Imaging; MRV: Magnetic Resonance Imaging; OR: Operation Rooms; SPSS: Statistical Package of Social Science.

\section{Declarations}

\section{Ethics approval and consent to participate}

This study was approved by the ethics committee of the Department of Neurosurgery, Kasr Alainy Faculty of Medicine, Cairo University on the 9th of June 2018. All participants provided informed written consent to participate in the study.

\section{Consent for publication}

Not applicable.

\section{Availability of data and materials}

The datasets used and/or analyzed during the current study are available from the corresponding author on reasonable request.

\section{Competing interests}

The authors declare that they have no competing interests.

\section{Funding}

Not applicable.

\section{Author's contributions}

H.S. collected, analyzed and interpreted the patient's data, M.A plotted the study design and drafted the manuscript. All authors read and approved the final manuscript

\section{References}


1. Omay SB, Barnett GH. Surgical navigation for meningioma surgery. J Neurooncol [Internet]. 2010 Sep;99(3):357-64. Available from: http://dx.doi.org/10.1007/s11060-010-0359-6

2. Paleologos TS, Wadley JP, Kitchen ND, Thomas DGT. Clinical Utility and Cost-effectiveness of Interactive Image-guided Craniotomy: Clinical Comparison between Conventional and Image-guided Meningioma Surgery [Internet]. Vol. 47, Neurosurgery. 2000. p. 40-8. Available from:

http://dx.doi.org/10.1097/00006123-200007000-00010

3. Kelly PJ, Goerss SJ, Kall BA. Evolution of contemporary instrumentation for computer-assisted stereotactic surgery. Surg Neurol [Internet]. 1988 Sep;30(3):204-15. Available from:

http://dx.doi.org/10.1016/0090-3019(88)90273-x

4. Rohde V, Spangenberg P, Mayfrank L, Reinges M, Gilsbach JM, Coenen VA. Advanced neuronavigation in skull base tumors and vascular lesions. Minim Invasive Neurosurg [Internet]. 2005 Feb;48(1):13-8.

Available from: http://dx.doi.org/10.1055/s-2004-830179

5. Sun G-C, Chen X-L, Yu X-G, Zhang M, Liu G, Hou B-K, et al. Functional Neuronavigation-Guided Transparieto-Occipital Cortical Resection of Meningiomas in Trigone of Lateral Ventricle. World Neurosurg [Internet]. 2015 Sep;84(3):756-65. Available from:

http://dx.doi.org/10.1016/j.wneu.2015.04.057

6. Willems PWA, van der Sprenkel JWB, Tulleken CAF, Viergever MA, Taphoorn MJB. Neuronavigation and surgery of intracerebral tumours. J Neurol [Internet]. 2006 Sep;253(9):1123-36. Available from: http://dx.doi.org/10.1007/s00415-006-0158-3

7. Hong CK, Hong JB, Park H, Moon JH, Chang JH, Lee KS, et al. Surgical Treatment for Falcotentorial Meningiomas. Yonsei Med J [Internet]. 2016 Jul;57(4):1022-8. Available from:

http://dx.doi.org/10.3349/ymj.2016.57.4.1022

8. Sun T, Jiang ZQ, Han Y, Zheng XL, Dong XH, Zhang SJ, et al. [Comparison of the accuracy of neuronavigation and linear measurement in the positioning of parasagittal meningioma]. Zhonghua $\mathrm{Yi}$ Xue Za Zhi [Internet]. 2019 Jan 29;99(5):384-7. Available from:

http://dx.doi.org/10.3760/cma.j.issn.0376-2491.2019.05.013

9. Wong GK, Poon WS, Lam MK. The impact of an armless frameless neuronavigation system on routine brain tumour surgery: a prospective analysis of 51 cases. Minim Invasive Neurosurg [Internet]. 2001 Jun;44(2):99-103. Available from: http://dx.doi.org/10.1055/s-2001-15998

10. Bir SC, Konar SK, Maiti TK, Thakur JD, Guthikonda B, Nanda A. Utility of Neuronavigation in Intracranial Meningioma Resection: A Single-Center Retrospective Study. World Neurosurg [Internet]. 2016 Jun;90:546-55.e1. Available from: http://dx.doi.org/10.1016/j.wneu.2015.12.101

11. Khaldi A, Helo N, Schneck MJ, Origitano TC. Venous thromboembolism: deep venous thrombosis and pulmonary embolism in a neurosurgical population [Internet]. Vol. 114, Journal of Neurosurgery. 2011. p. 40-6. Available from: http://dx.doi.org/10.3171/2010.8.jns10332

12. Golebiowski A, Drewes C, Gulati S, Jakola AS, Solheim O. Is duration of surgery a risk factor for extracranial complications and surgical site infections after intracranial tumor operations? Acta Neurochir [Internet]. 2015 Feb;157(2):235-40; discussion 240. Available from:

http://dx.doi.org/10.1007/s00701-014-2286-3

13. Oh T, Safaee M, Sun MZ, Garcia RM, McDermott MW, Parsa AT, et al. Surgical risk factors for post- 
operative pneumonia following meningioma resection. Clin Neurol Neurosurg [Internet]. 2014 Mar;118:76-9. Available from: http://dx.doi.org/10.1016/j.clineuro.2013.12.017

14. Procter LD, Davenport DL, Bernard AC, Zwischenberger JB. General surgical operative duration is associated with increased risk-adjusted infectious complication rates and length of hospital stay. J Am Coll Surg [Internet]. 2010 Jan;210(1):60-5.e1-2. Available from:

http://dx.doi.org/10.1016/j.jamcollsurg.2009.09.034

\section{Figures}

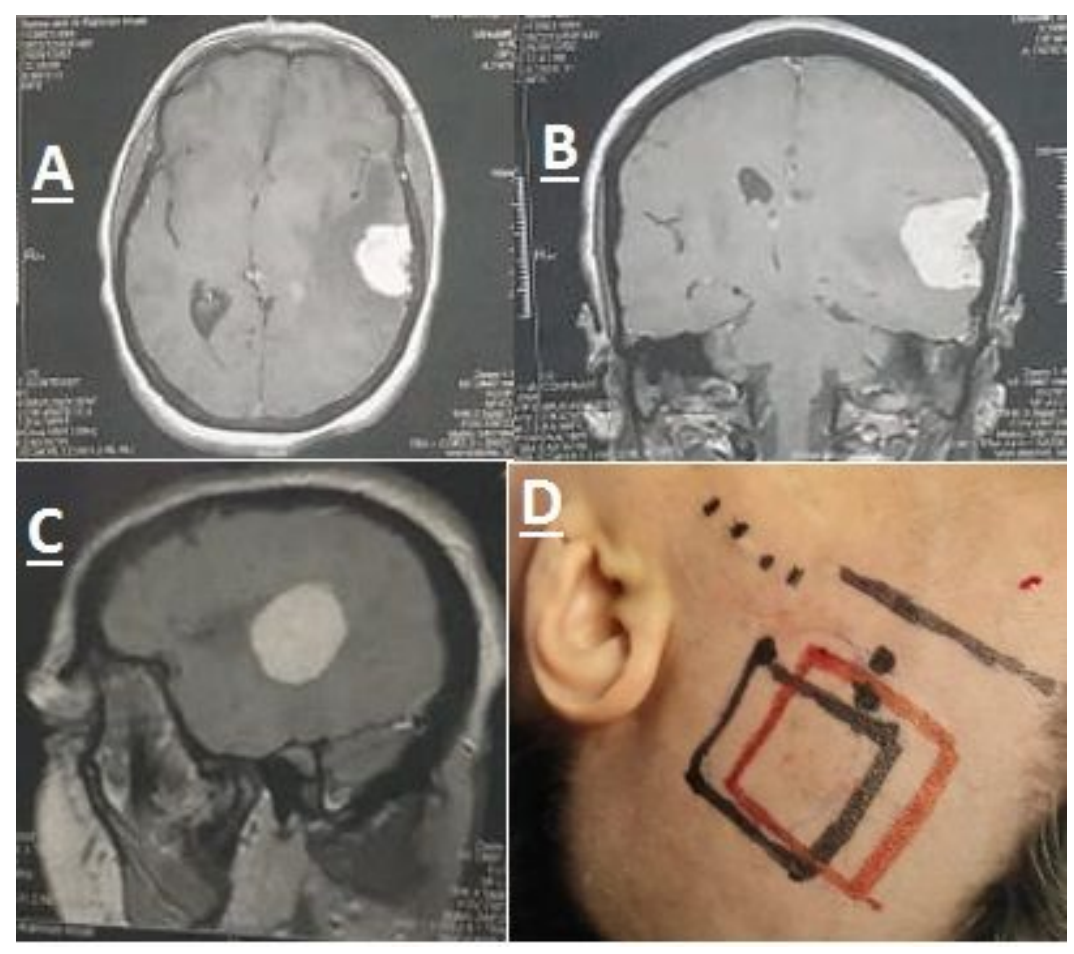

\section{Figure 1}

$A, B$ and $C$ pictures show contrast MRI study for a convexity meningioma case. $D$ picture shows the both methods of localization in this case, the black rectangle is the craniometric localization, while the red rectangle is the navigation assisted localization. 